\title{
Chylopericardium: a rare complication of a Waterston shunt
}

\author{
J R L HAMILTON, ^ H C MULHOLLAND, † J CLELAND* \\ From the ${ }^{\star}$ Department of Cardiac Surgery, Royal Victoria Hospital; and the $\dagger$ Department of Paediatric \\ Cardiology, Royal Belfast Hospital for Sick Children, Belfast, Northern Ireland
}

SUMMARY A case of chylopericardium occurring after a Waterston shunt was successfully managed by pericardial drainage of chyle and substitution of dietary fats with medium chain triglycerides.

Chylous pleural effusion is a well recognised complication after thoracic surgery. The accumulation of chyle in the pericardium sufficient to cause tamponade, however, is a rare complication of cardiac surgery and was first described in 1971 by Thomas and McGoon. ${ }^{1}$ The aetiology of chylopericardium is uncertain and because the condition is so rare the correct treatment has yet to be established. We report a case of this unusual complication in a 5 month old infant after a Waterston shunt and discuss the management of this condition.

\section{Case report}

A male infant weighing $1.8 \mathrm{~kg}$ was born at 33 weeks' gestation after the spontaneous onset of labour. $\mathrm{He}$ was small for dates, but there was nothing unusual in the antenatal history. Cyanosis was not clinically apparent, an electrocardiogram showed sinus rhythm with left ventricular dominance, and the chest $x$ ray film showed an increased cardiothoracic ratio. A systolic murmur was heard and he was referred for assessment. Cardiac catheterisation showed pulmonary atresia with a hypoplastic right ventricle, widely patent ductus arteriosus, and a large atrial septal defect. As his condition was stable, surgical intervention was not warranted and he was discharged. He was readmitted at the age of five months because of failure to gain weight and mild cyanosis, and it was felt that a palliative shunt was required.

A standard Waterston shunt by the retrocaval

Requests for reprints to Mr J R L Hamilton, FRCS, Department of Cardiac Surgery, Royal Victoria Hospital, Grosvenor Road, Belfast BT12 6BA, Northern Ireland. approach was carried out through a right lateral thoracotomy. The surgical procedure was uneventful and a good shunt murmur was audible after operation. The pleural drain was removed the following day. Two days later, however, an increase in heart size was noted on the chest $x$ ray film; one week postoperatively the presence of a large pericardial effusion was confirmed by echocardiography but there were no specific features to suggest chylopericardium. Despite increased diuretic therapy the size of the effusion as assessed by echocardiography continued to increase.

Three weeks postoperatively surgical drainage was performed through a small sub-xiphoid incision; $200 \mathrm{ml}$ of milky fluid was removed from the pericardium and a pericardial drain was left in situ. Laboratory analysis of the aspirated fluid showed the presence of chylomicrons and this confirmed the clinical diagnosis of chylopericardium. The patient was started on a diet in which dietary fats were replaced by medium chain triglyceride supplements. About $20 \mathrm{ml}$ of chyle drained away each day for the next five days; drainage ceased after one week and the drain was removed. An echocardiogram two weeks later confirmed that no fluid had reaccumulated in the pericardium. Follow up three months later showed a heart of normal size on chest $x$ ray film and normal echocardiographic appearance.

\section{Discussion}

The first case of chylopericardium after cardiac surgery was reported in 1971 by Thomas and McGoon. ${ }^{1}$ Feteih et al reviewed nine further cases and added their own. ${ }^{2}$ Since this review, further 
cases have been added by Rose $e t \mathrm{al}^{s}$ and Pugliese $e t$ $a l .{ }^{4}$ These 13 cases span the full range of ages from infants to adults and cover the whole spectrum of cardiac operations from palliative shunts to definitive procedures.

Our case, like those reported by Hawker et $a l^{5}$ in 1972 and Jacob and colleagues ${ }^{6}$ in 1974, occurred in a patient who had had a Waterston shunt. The aetiology of chylopericardium after cardiac surgery is not clear but it seems that there is a definite risk of this complication after a Waterston shunt. Transection of an important lymphatic channel is obviously a factor, but such an event has only been described occasionally, despite the high frequency of anatomical variations in the course of the thoracic duct. In the case described by Thomas and McGoon, thrombosis of the left subclavian vein secondary to insertion of an external jugular vein cannula was described and they believed that this thrombosis had obstructed the end of the thoracic duct and produced high lymphatic pressures. ${ }^{1}$ A similar aetiology was possible in the case described by Kansu $e t \cdot a l^{7}$ and Rose $e t a l^{3}$; however, in our patient venous access was maintained by a right internal jugular cannula.

The interval from operation to appearance of the chylopericardium ranges from four days, as in our case, to five weeks. ${ }^{5}$ This suggests that the aetiological development of the condition depends on whether damage to the major pericardial lymphatic occurs at operation or is a result of later fibrosis. Those who have reported cases of chylopericardium have not agreed on the management of such patients. Providing that no major lymphatic vessel had been damaged, as shown by excessive pericardial drainage or rapid reaccumulation of chyle after aspiration, most cases settled with conservative management. Adequate drainage of the pericardium is essential and this is most effectively established by the insertion of a pericardial drain via the sub-xiphoid approach. Chyle formation can be reduced by controlling the dietary intake of fats. Fats are hydrolysed in the gut to glycerol and fatty acids and these long chain fatty acids are reesterified to triglycerides and passed into the lymphatics as chylomicra. Medium chain triglycerides, however, are not re-esterified but pass directly into the portal venous blood. Thus the substitution of dietary fats with medium chain triglycerides is an effective method of reducing chyle formation, and this approach was successful in our case and that of others.

\section{References}

1 Thomas CS Jr, McGoon DC. Isolated massive chylopericardium following cardiopulmonary bypass. $\mathcal{f}$ Thorac Cardiovasc Surg 1971; 61: 945-8.

2 Feteih W, Rao PS, Whisennand $\mathrm{HH}$, Mardini MK, Lawrie GM. Chylopericardium: new complication of Blalock-Taussig anastomosis. $\mathcal{F}$ Thorac Cardiovasc Surg 1983; 85: 791-4.

3 Rose DM, Colvin SB, Danilowicz D, Isom OW. Cardiac tamponade secondary to chylopericardium following cardiac surgery: case report and review of the literature. Ann Thorac Surg 1982; 34: 333-6.

4 Pugliese P, Santi C, Eufrate S. Isolated chylopericardium after successful correction of total anomalous pulmonary venous drainage. $\boldsymbol{f}$ Cardiovasc Surg (Torino) 1984; 25: 75-7.

5 Hawker RE, Cartmill TB, Celermajer JM, Bowdler JD. Chylous pericardial effusion complicating aorta-right pulmonary artery anastomosis. $\mathcal{F}$ Thorac Cardiovasc Surg 1972; 63: 491-4.

6 Jacob T, de Leval M, Stark J, Waterston DJ. Chylopericardium as a complication of aorta-pulmonary shunt. Arch Surg 1974; 108: 870-1.

7 Kansu E, Fraimow W, Smullens SN. Isolated massive chylopericardium. Complication of open heart surgery for aortic valve replacement. Chest 1977; 71: 408-10. 